\title{
Designing and Implementing a Video Game to Assist Teaching-Learning Process of Numerical Expressions
}

\author{
Edgar Manuel Cano Cruz, Juan Gabriel Ruiz Ruiz \\ Computer Science Department, Universidad del Istmo, Ixtepec, Mexico
}

Email address:

ie.edgarcano@gmail.com (E. M. C. Cruz)

To cite this article:

Edgar Manuel Cano Cruz, Juan Gabriel Ruiz Ruiz. Designing and Implementing a Video Game to Assist Teaching-Learning Process of Numerical Expressions. Education Journal. Vol. 4, No. 5, 2015, pp. 201-206. doi: 10.11648/j.edu.20150405.13

\begin{abstract}
Nowadays, there has been a real change in the traditional methodology for learning and teaching; the teaching of mathematical subject needs to identify the real necessities of students to avoid deficiencies in static classrooms. The benefits of the digital game based learning approach as a learning paradigm are widely recognized, because they support learning environments where students are actively related in implementing their own knowledge; passing through passive to active learning states. This article describes the development of an educational video game that aims to help first semester high school students to improve their understanding of the Numerical Evaluation of Algebraic Expressions. The game is verified by testing to ensure that the graphic and textual components show the correct communicability interfaces and transmit efficiently the intent of the educational content. The results of communicability testing were analysed on the same day and show that interfaces with greater communicability problems were those that concentrate more on graphical and textual components.
\end{abstract}

Keywords: Communicability Testing, DGBL, Video Games, Educational Technology

\section{Introduction}

Since the first attempts to include educational technologies in various school systems around the world, educational progress has been too slow. Pelgrum \& Voogt (2009) found a number of barriers that have slowed or stalled the apparent advantage of these types of educational tools in the teachinglearning process: "Students continue to show aversion to the use and usefulness of ICT, especially in areas related to mathematics, use new strategies for educational technology where more interactive and dynamic interfaces are needed" [1]. In this context, in the first decade of the twenty first century the popularity of video games in education has become a new educational technology, providing students an effective and fun environment to support learning processes.

This paper reports the results obtained from a round of communicability tests performed on a video game prototype. The goal of the video game is to help high school students improve their understanding of the Numerical Evaluation of Algebraic Expressions, which is part of Algebra. The aim is to verify how effectively the graphical and textual components communicate the creators' intention. A qualitative approach was adopted to perform the tests at an early stage of the process. Printout prototypes and a think aloud protocol were used. Four non-potential users were involved in the test, which took place in a classroom. The results were analyzed on the same day. They reveal that the interface with the highest concentration of textual and graphical components present the most important communicability problems.

The paper is organized as follows: section 2 is a brief review of digital games based learning (DGBL); section 3 is a review of related works about DGBL and low cost communicability methods in usability; section 4 describes the evaluated prototype features; section 5 presents an educational methodology proposal for the use of educational video games; section 6 describes the applied procedure to carry out the communicability tests and shows the results obtained from the tests of our video game; and finally, section 7 presents the conclusion of this work.

\section{DGBL: A Brief Review}

The lack of creativity in teaching mathematics is one of the factors that have caused boredom and a loss of interest in the subject. DGBL has been considered an effective method to significantly improve the motivation and feelings of students through the learning process in different areas of knowledge [2]. DGBL is a learning approach that uses computer games 
as a means of transporting educational content in order to empower and motivate students to study. The word "game" attached to digital applications in an instructional context is defined by Salen \& Zimmerman (2004) in Rules of Play: Game Design Fundamentals as "A game is a system in which players are encouraged to resolve an artificial conflict, defined by rules, which results in a measurable output" [3]. Although the definition should be amended to apply to a learning context, adding the concept of emotional reactions based on the idea of the fun factor presented by Raph Koster. In A Theory of Fun, Koster defines a game as "a system in which players are to complete an abstract challenge, defined by rules, interaction and feedback, having as output a result and often quantifiable to triggering an emotional reaction" [4]. In this sense, the theory based on the interaction with a digital game holds that the player learns through various ways: listening to instructions, reading challenges or deciding on issues in real time to solve a problem, which triggers their emotional reactions while they try to solve a situation found in the dynamics of the game. For example, Hung, Huang, \& Hwang, (2014), show that a learning environment based on video games reduces anxiety of children in mathematics and improves their confidence and self-confidence in learning this matter.

Also, Kim \& Chang (2010) show that students who use a computer every day to play math games in school reduce significantly their aversion to mathematics compared to students who do not play. However, not all educational video games fulfill their purpose of conveying a correct communicability with users because of their confusing and poor interfaces. One example is the case of Donkey Kong Jr. Math, released by Nintendo in 1985, which was a failure in popularity and sales: "It was a horrible game and a poor educational tool in 1985, and it's still just as devoid of merit more than twenty years later. This game is too low for edutainment games and is one of the worst Nintendo games ever made!" [5].

With regard to the evolution of educational games, Egenfeldt-Nielsen's doctoral thesis and subsequent publications $[6,7]$ identified educational game generations on the basis of learning theories in use (see Figure1).

\begin{tabular}{l|l|l} 
First Generation & Second Generation & Third Generation \\
\hline \begin{tabular}{l|l} 
Control input, \\
direct learning
\end{tabular} & $\begin{array}{l}\text { Scalfolding, chunking, } \\
\text { perception, facilitating }\end{array}$ & $\begin{array}{l}\text { Meaningful, social, } \\
\text { interaction, framing, } \\
\text { culture }\end{array}$ \\
\hline Behaviourism & \begin{tabular}{|l|l} 
Cognitivism \\
Constructivism
\end{tabular} & $\begin{array}{l}\text { Socio-cultural } \\
\text { Situated Learning } \\
\text { Constructionism }\end{array}$ \\
\hline
\end{tabular}

Figure 1. Evolution of educational video games.

The evolution of the design has led to more sophisticated visual aspects, three-dimensional effects, virtual reality, etc. However, a good graphic development is not sufficient to keep the attention and interest of the player. Story lines and storytelling are also important factors for the success of a game [8].

As for the classification of video games, the industry, developers and academics use different taxonomy to differentiate the types of games (see Table 1).

Table 1. Communicability evaluation questions at each interface.

\begin{tabular}{ll}
\hline Category & Description \\
\hline $\begin{array}{l}\text { Action/platform } \\
\text { games }\end{array}$ & $\begin{array}{l}\text { These games are reaction based; most of the games } \\
\text { of the first generation are action games. } \\
\text { The player solves a number of tests in order to } \\
\text { progress through a virtual world. } \\
\text { These games involve fighting against computer- } \\
\text { Fighting games }\end{array}$ \\
$\begin{array}{l}\text { controlled characters or controlled by other players. } \\
\text { Ruman players assume the characteristics of some } \\
\text { games }\end{array}$ & $\begin{array}{l}\text { person or creature. } \\
\text { The player has to succeed within some simplified } \\
\text { recreation of a place or situation to achieve a } \\
\text { particular goal. }\end{array}$ \\
Simulation & $\begin{array}{l}\text { These games are based on sports. } \\
\text { These games recreate a historical or fictional } \\
\text { situation to allow a player to devise an appropriate } \\
\text { Strategy to achieve a goal. }\end{array}$ \\
\hline
\end{tabular}

\section{Related Work: DGBL and Communicability}

\section{1. $D G B L$}

Much debate in the scholarly literature and among the public has focused on the positive and negative influences of playing video games among adolescents. A great deal of this debate has focused on harmful effects such as aggressive behavior and pathological overuse [9]; however, evidence for harmful effects remains in short supply. In this context, the objective of DGBL is to create new ways to transmit knowledge through the use of ICT [10, 11, 12]. Hwang, Hung and Chen in [13], reported a peer assessment based game development approach, which was applied to an elementary school science course. The experimental results showed that the approach helped the students in improving their deep learning status in terms of "in-depth thinking," "creativity," and "motivation". Chu and Zhang presented an educational computer game for migratory bird identification based on a two-tier test approach. It was found that the proposed approach significantly promoted the students' learning motivation, learning achievements and technology acceptance degree in comparison with those who learned with the conventional e-learning approach [].

In the research "Embedding diagnostic mechanisms in a digital game for learning mathematics," Hung, Huang and Hwang presented a mathematics game with diagnostic mechanisms and showed the effectiveness of the approach in enhancing students' interest and reducing their anxiety in learning mathematics by conducting a learning activity in an elementary school school [14].

Vogel [15], concluded from 32 empirical studies, that the inclusion of video games in the students' learning process 
results in higher cognitive achievement in comparison with traditional learning methods. In his work Learning to play games or playing games to learn? Alan Amory (2010) shows a health education case study with a group of teenagers in the urban area called Soweto of the city of Johannesburg in Gauteng, South Africa. He discusses the advantages of using educational video games with students aged 14 to 19 to teach about the biology of cancer, the symptoms of malaria, tuberculosis and HIV. Amory says: "They were proud of their achievements and mentioned how their different roles related to collaboration and competition that helped them to complete the game. Not only did they enjoy playing the game, but they felt that their experience empowered them to support their community" [16]. Other research related to learning with DGBL was carried out by Yien (2010) in Taiwan. Their work studied the effect of video games and their application in teaching primary-education children the basic concepts of nutrition, and obtained the following conclusions: "most of the students revealed quite positive attitudes toward the use of the game-based learning approach in nutrition education. An in-depth analysis showed that there was no significant difference between genders in terms of nutrition knowledge and learning attitudes" [17].

\subsection{Communicability}

The idea that video games have a positive effect on the affective aspects of learning and encourages a positive attitude is widely supported [1]. However, diverse results have been obtained from video games regarding cognitive achievements and academic performance. Indeed, some games do not comply with the objectives of an adequate graphic interface. To fill this gap, the present research uses the method of communicability, which has been insufficiently exploited in Human Computer Interaction (HCI) in comparison to the topic of usability $[18,19]$. According to [20], communicability is a theoretical field that is a response to the practical fusion of four theoretical fields: Perception, Semiology, Rhetoric of image and Syntax of image. This fusion leads to the understanding of the referential framework for the development of users' graphic interfaces. The author suggests that a way to measure the effectiveness of the graphic components of an interface can be done through their interaction or their perception. In this sense, communicability is a fundamental aspect that should be considered and evaluated in the interface design because the effectiveness of the different iconographic and textual elements of interactive systems depends upon communicability [21]. Both communicability and usability can be evaluated during the development process to identify the problems that obstruct the user from understanding what needs to be done in an application. From that point, improvements in the Graphic User Interfaces (GUIs) and text can be done. This process involves developing the visual level of the interface, where the necessary iconic-verb elements establish an effective communication with the user.

\section{Development of the Video Game}

The video game is designed to support the first semester high school students' about of Numerical Evaluation of Algebraic Expressions subject. The video game has four levels with ten questions in each level. One algebraic expression is presented in each question with a list of values. The user has to substitute these values in the algebraic expression and needs to solve mentally the operations to find the right answer. To advance to the next level, seven questions must be answered correctly. The video game has an initial user interface, instructions section, levels section and the main page of the game. The initial user interface allows users to restart the video game, review the instructions and exit the video game. Likewise, the instructions interface informs the user about the objectives, the rules and the way to interact with the video game. The levels interface allows users to access different levels offered by the video game.

The page interface allows the user to move to the right and to the left by means of a virtual character (see Figure 2). In this sense, the avatar was developed with the sprites of the main character of the Braid video game, called Tim. Tim was designed by the artist David Hellman and its sprites have released by Hellman in his web page [22]. About our avatar (called Cecyboy), first, we called for a cartoon contest, and then with the support of a graphic tablet, the cartoon chosen was digitalized. The cartoon elected was inspired by the average complexion of the Mexican student.

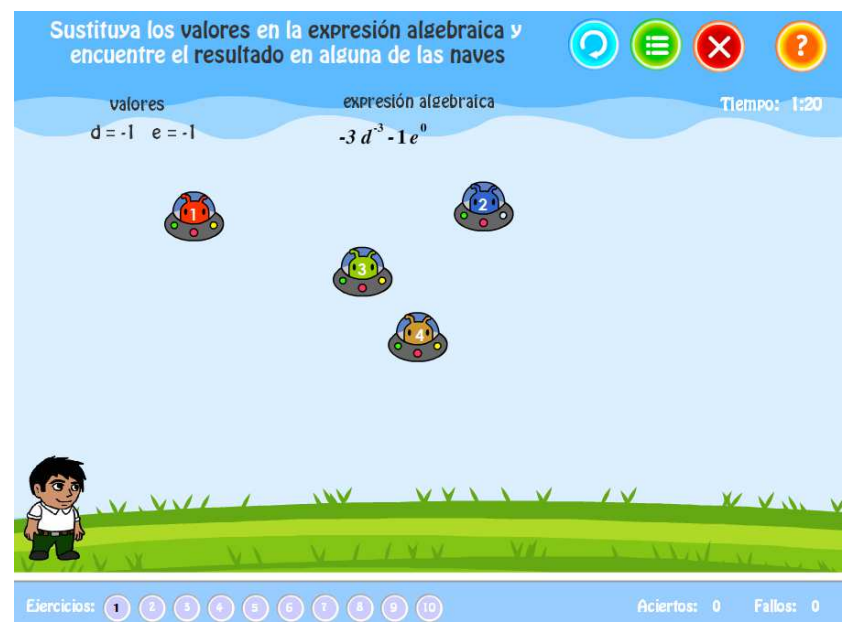

Figure 2. Main page of the mathematical spaceships video game.

About of the functionality of the Cecyboy, can shoot spaceships displaying the possible choices by means of command actions. Figure 1 shows the main page of the video game, where the user tests his knowledge. On the top-right side of this interface there is a set of buttons which allows users to restart the current level, return to the levels interface, quit the video game and get help about the objectives, rules and how to interact with the video game. On the top central area of the page there is an algebraic expression, one list of values which the user has to substitute on the expression and a set of spaceships with different results. The avatar must shoot and destroy the spaceships with the right result. At the 
bottom there is one bar that indicates the number of each exercise per level, and the number of right and wrong answers given by the users.

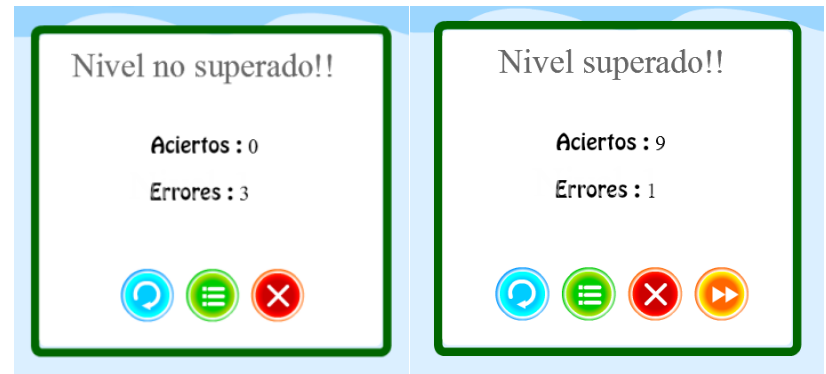

Figure 3. Dialog boxes displayed at the end of the levels.

Figure 3 shows the dialog boxes displayed by the video game when the user has passed a level or not. When the user has not passed a level, the left dialog box offers the possibility to restart the game, return to the levels menu or quit the game. On the other hand, when the user passes a level, the dialog box on the right displays the button to advance to the next level. Both dialog boxes show the total number of right and wrong answers obtained in the current level.

\section{Educational Methodology}

The way to use the Mathematical Spaceships video game is with a specific methodology. The methodology proposes the creation of a setting where the video game is developed specifically to cover the topics included in a lesson plan. The lesson plan has been carefully designed by teachers and educators for algebra study. We suggest using the video game between 10 and 15 hours per study unit in the classroom (three evaluations in four months). The suggested methodology to incorporate video games in the teachinglearning process contains four phases (see Figure 3):

1 Experimentation: During the first lessons, the learning objectives and the activities designed to reach these objectives are defined. There is an emphasis on the feedback from the class to clarify any ambiguities found in the video game. In this sense, we planned a several theory block unities specified by Table 2 .

2 Reflection: At the end of each lesson, the results obtained by each group are compared. The various study strategies used by each group are analysed.

3 Activity: Learning activities are designed specifically for the video game. In this phase, the students use the video game. In addition, they do other comprehension activities such as reading book chapters and researching on the internet.

4 Discussion: Throughout the process, the documents are designed for each group to indicate the activities completed in the game and to present an analysis of the strategies used. The documents must be filled out at the end of each session. Before each session, the teachers are provided with a list of topics to be discussed in groups. At the end, what was learned through the proposed activities is evaluated.

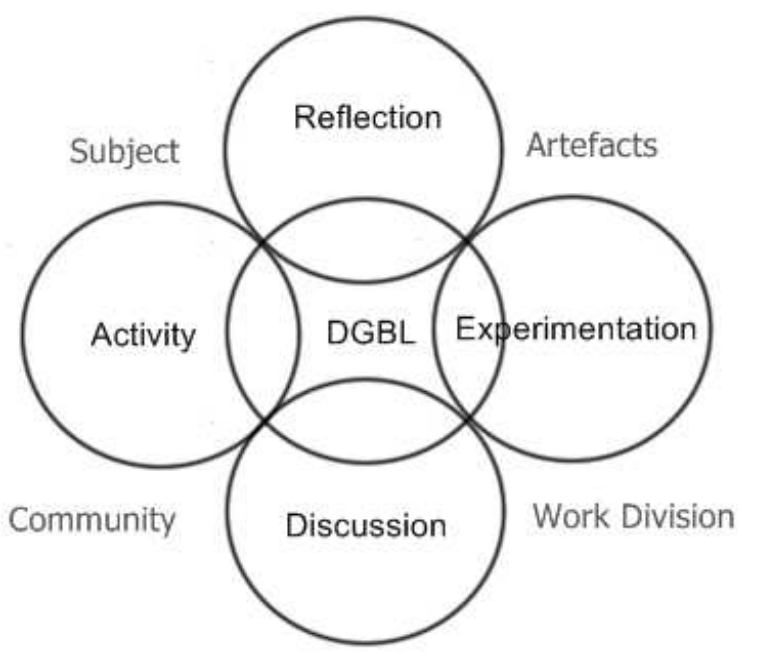

Figure 4. Learning process supported by an educational video game.

\section{Usability Test}

The tests were carried out during the initial stage of the development process. The focus was qualitative. Paper prototypes and a think aloud protocol were used.

\subsection{Communicability Test}

In order to evaluate the communicability, the method developed by Góngora et al. [19], was used. Indeed, it provides the simplest means of methodological comparison with other tests that were examined. Two computer science/information science students in their eighth semester of university and a teacher were in charge of the communicability tests.

The teacher was in charge of planning. One student acted as a facilitator while the other was responsible for taking notes on the information obtained during the tests (see Figure 5).

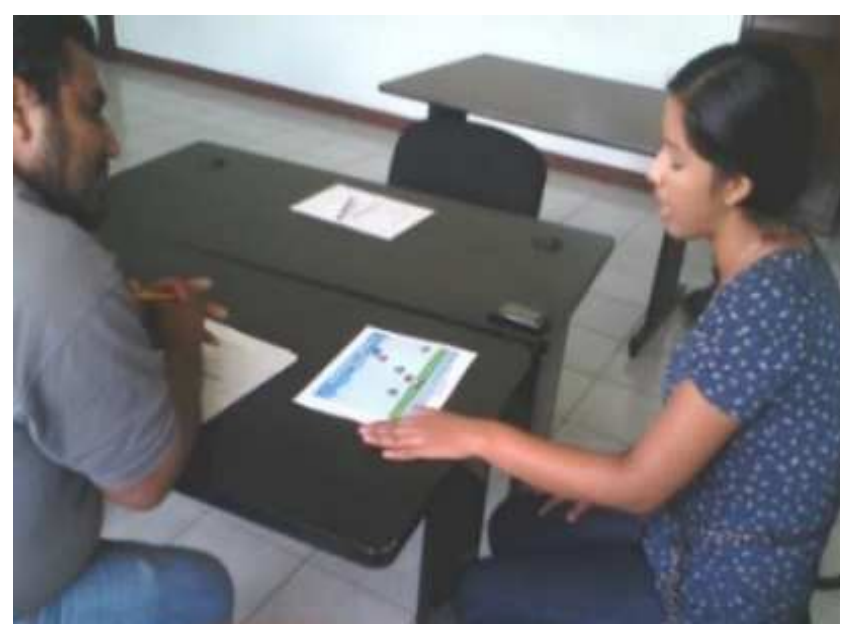

Figure 5. Communicability tests 
Table 2. Communicability evaluation questions at each interface

\begin{tabular}{|c|c|}
\hline Interface & Questions \\
\hline Start up & $\begin{array}{l}\text { - How would you start the game? } \\
\text { - How would you access video game instructions? } \\
\text { - How would you exit the video game? } \\
\text { - What is the objective/mission of the game? }\end{array}$ \\
\hline Instructions & $\begin{array}{l}\text { - What are the rules of the game? } \\
\text { - How should you interact with the game? }\end{array}$ \\
\hline Levels & $\begin{array}{l}\text { - How would you access the first level of the game? } \\
\text { - Is the objective of the level clear? }\end{array}$ \\
\hline $\begin{array}{l}\text { Main screen of } \\
\text { video game }\end{array}$ & $\begin{array}{l}\text { What does the game consist of and what do you have } \\
\text { to do? } \\
\text { - What function do the buttons in the circles in the } \\
\text { bottom left-hand corner of the screen perform? } \\
\text { - What does the boldest number in any one of the } \\
\text { - Which level are you on now? } \\
\text { - How would you know how many successful and } \\
\text { failed attempts you have made? }\end{array}$ \\
\hline $\begin{array}{l}\text { Unsuccessful } \\
\text { level }\end{array}$ & $\begin{array}{l}\text { - How many successes and failures did you have on } \\
\text { the first level? } \\
\text { - What is the function of every button? }\end{array}$ \\
\hline $\begin{array}{l}\text { Successful } \\
\text { level }\end{array}$ & $\begin{array}{l}\text { - How many successes and failures did you have on } \\
\text { the first level? } \\
\text { - What is the function of each button? }\end{array}$ \\
\hline
\end{tabular}

Unlike in the usability tests, tasks were not defined. Nor was a quantitative analysis performed. Questions were designed for every interface. The objective of the communicability tests was to verify that the participants interacted with the graphic and text components of the video game prototype in the manner that the designers had intended. When users interpreted the functions of graphic and text components differently than what was intended, the facilitator tried to identify what might have confused them. Participants were asked for suggestions on how to correct deficiencies.

Notes were taken by a student assistant on the information provided by the participants during the tests. Four nonpotential users were chosen according to the approach of [23]. Three of the participants were female. Two were nineteen years old. The other was twenty. The fourth participant was a twenty-year-old male. Two of the women possessed basic knowledge of video games. The other two participants possessed intermediate knowledge.

The results of the study can be found below.

\subsection{Previous Results}

The information provided was recorded as notes with the help of another student during testing. Table 3 lists only the interfaces where important problems were observed. Details are described here:

Table 3. Communicability problems identified

\begin{tabular}{|c|c|c|}
\hline Interface & $\begin{array}{l}\text { Graphical/textual } \\
\text { component }\end{array}$ & Observations \\
\hline Instructions & $\begin{array}{l}\text { - Objective } \\
\text { - Rules } \\
\text { - How to } \\
\text { interact with } \\
\text { the game }\end{array}$ & $\begin{array}{l}\text { Four participants commented that } \\
\text { the lack of clear instructions on these } \\
\text { components did not clearly explain } \\
\text { what to do and how to interact with } \\
\text { the game. }\end{array}$ \\
\hline
\end{tabular}

\begin{tabular}{|c|c|c|}
\hline Interface & $\begin{array}{l}\text { Graphical/textual } \\
\text { component }\end{array}$ & Observations \\
\hline $\begin{array}{l}\text { Main screen } \\
\text { of the video } \\
\text { game }\end{array}$ & $\begin{array}{l}\text { Exit and restart } \\
\text { buttons } \\
\text { - List of numeric } \\
\text { values of the } \\
\text { algebraic } \\
\text { expression }\end{array}$ & $\begin{array}{l}\text { One participant confused the exit } \\
\text { button function with the delete } \\
\text { function, and the restart button of the } \\
\text { game with the restart button of the } \\
\text { exercise when his answer was } \\
\text { wrong. }\end{array}$ \\
\hline
\end{tabular}

Based on the communicability problems presented by some graphic and text components of interfaces, users suggested:

1 Add an animation of the main character during the start interface because it is not appealing.

2 Increase the font size of the list of numeric values and algebraic expressions.

3 Write clearer instructions for the objective, mission, rules and how to interact with the game.

4 On the main screen of the game, highlight the keywords in red; add some text to the buttons located on the topright corner to reduce ambiguity about their functionality.

5 Modify the text of the dialogue box shown when a user does not pass a level. Users said that it was abrupt and it discouraged them.

\section{Conclusions}

The capacity of video games to engage and challenge players through increasingly complex and demanding stages and the range of cognitive, and sociocultural practices generated by games and game play have led to increased interest in the use and study of video games in schools.

According to the results of the verification phase, we have a potential video game with an interface and content of algebraic expressions to be used within the curriculum of the high school system in Oaxaca, Mexico. Players were pleased with the results from the interaction with the game, which encouraged them to give feedback about what could be redesigned and improved in the game. In another phase, the project will be validated to check whether it is an effective tool in a real course, comparing two groups of students. A first group will follow a normal or traditional course of Mathematics I and the second group will follow the same course but with the help of the set of games developed here.

We are planning to carry out specific projects of educational video games to support the process of teaching and learning at lower education levels, mainly in mathematics and related areas.

The feedback obtained from participants during the testing phase shows clearly that some graphic and text components, mainly in the instruction and main screen interfaces, do not communicate effectively what their creators intended.

Working with the approach of low-cost usability methods is beneficial, because the financial, material and time resources are minimal, and the resulting feedback is important. In our case, planning and questionnaires were easily designed and results were analyzed the same day the 
testing phase was carried out. This approach speeds up the learning process about graphic and text components that should be eliminated, adjusted or kept on interfaces.

We are planning to design and develop video tutorials and more video games according to the curriculum of the Centro de Estudios Científicos y Tecnológicos del Estado de Oaxaca (CECyTEO) for Mathematics II and Trigonometry with Analytical Geometry.

\section{References}

[1] W. Pelgrum and J. Voogt, "School and teacher factors associated with frequency of ICT use by mathematics teachers: Country comparisons.," Education and Information Technologies, vol. 14, no. 4, pp. 293-298, 2009.

[2] N. A. Zin, A. Jaafar and W. S. Yue, "Digital game-based learning (DGBL) model and development methodology for teaching history," WSEAS Transactions on Computers, vol. 8, no. 2, pp. 322-333, 2009.

[3] K. Salen and E. Zimmerman, Rules of Play: Fundamentals of Game Design, MIT Press, 2004.

[4] R. Koster, A theory of fun for game design, Scottsdale, AZ : Paraglyph Press, 2005.

[5] GamesSpott, "What do you get if you cross Donkey Kong Jr with the most hated school subject on the planet? Donkey Kong Jr Math!!!!," 2104 2014. [Online]. Available: http://www.gamespot.com/donkey-kong-jr-math/. [Accessed $24092014]$.

[6] S. Egenfeldt-Nielsen, "Beyond edutaiment," Unpublished dissertation, 2005.

[7] S. Egenfeldt-Nielsen, "Third Generation Educational Use of Computer Games," Journal of Educational Multimedia and Hypermedia, vol. 16, no. 3, 2007.

[8] F. Begoña, Videojuegos y Aprendizaje, GRAÓ, 2008.

[9] C. J. Ferguson, "Video Games," in Encyclopedia of Adolescence, Springer New York, 2014, pp. 3040-3045.

[10] J. García-bárcena and A. García-crespo, "Game based learning: a research on Learning Content Management Systems," in Proceedings of the 5th WSEAS International Conference on Education and Educational Technology, Tenerife, Spain, 2006.

[11] A. Vasiliou and A. Economides, "Game-based learning using MANETs," in 4th WSEAS/ASME International Conference on Engineering Education (EE'07), Crete, 2007.

[12] J.-m. Yien and Y.-c. Lin, "A GAME-BASED LEARNING APPROACH TO IMPROVING STUDENTS '," The Turkish Online Journal of Educational Technology, vol. 10, no. 2, pp. 1-10, 2011.
[13] G. Hwang, H. Sung, C. Hung, I. Huang and C. Tsai, " Development of a personalized educational computer game based on students' learning styles," Educational Technology Research and Development, vol. 60, no. 4, pp. 623-638, 2012.

[14] C.-M. Hung, I. Huang and G.-J. Hwang, "Effects of digital game-based learning on students' self-efficacy, motivation, anxiety, and achievements in learning mathematics," Journal of Computers in Education, Vols. 10.1007/s40692-014-0008-8, 2014.

[15] J. VOGEL, D. VOGEL, J. CANNON-BOWERS, C. BOWERS, K. MUSE and M. WRIGHT, "COMPUTER GAMING AND INTERACTIVE SIMULATIONS FOR LEARNING: A META-ANALYSIS," JOURNAL EDUCATIONAL COMPUTING RESEARCH, vol. 34, no. 3, pp. 229-243, 2006.

[16] A. Amory, "Learning to play games or playing games to learn ? A health education case study with Soweto teenagers," Australasian Journal of Educational Technology, vol. 26, no. 6, pp. 810-829, 2010.

[17] J.-m. Yien and Y.-c. Lin, "A GAME-BASED LEARNING APPROACH TO IMPROVING STUDENTS' LEARNING ACHIEVEMENTS IN A NUTRITION COURSE," The Turkish Online Journal of Educational Technology, vol. 10, no. 2, pp. 1-10, 2011.

[18] C. Rusu, S. Roncagliolo, A. Figueroa, V. Rusu and D. Gorgan, "Evaluating the usability and the communicability of grid computing applications," in ACHI 2012 - 5th International Conference on Advances in Computer-Human Interactions, 2012.

[19] A. Góngora, A. Rodríguez, Y. León y T. Capote, «Guía para evaluar Usabilidad, Accesibilidad y Comunicabilidad en Aplicaciones,» Revista Antioqueña de las Ciencias Computacionales y la Ingeniería de Software, vol. 3, $\mathrm{n}^{\mathrm{o}} 2$, pp. 59-64, 2013.

[20] A. Correa, «Comunicabilidad, paradigma de la Interacción Humano-Computador. No Solo Usabilidad,» No Solo Usabilidad, vol. 1, n 9, 2010.

[21] M. Zelcer, "Interfaces intuitivas en dispositivos móviles de pantalla táctil," Revista de diseño de interacción, no. 6, pp. 4459, 2014.

[22] D. Hellman, "Braid graphics briefcase," Braid (C) Number None, Inc., 2008. [Online]. Available: http://www.davidhellman.net/braidbrief.htm. [Accessed 11 November 2014].

[23] S. Krug, Don't Make Me Think - A Common Sense Approach To Web Usability, New Riders, 2006. 